\title{
PUBLIC HEALTH RESEARCH
}

\section{Analisis Kualiti Hidup Pesakit Kanser Prostat di Hospital Universiti Kebangsaan Malaysia, Kuala Lumpur}

\author{
Norzaher Ismail ${ }^{*}$, Syafiq Taib $^{2}$, Siti Nor Mat ${ }^{3}$, Shamsul Azhar Shah ${ }^{3}$ and Nazarudin Safian \\ ${ }^{1}$ Pejabat Kesihatan Daerah Mersing, Jalan Ismail, 86800 Mersing, Johor. \\ ${ }^{2}$ Jabatan Kesihatan Negeri Johor (Kesihatan Awam), Jalan Persiaran Permai, Kempas Baru, 81200 Johor Bahru, \\ Johor. \\ ${ }^{3}$ Jabatan Kesihatan Masyarakat, Pusat Perubatan Unversiti Kebangsaan Malaysia, Cheras, Kuala Lumpur, \\ Malaysia.
}

*For reprint and all correspondence: Norzaher Ismail, Pejabat Kesihatan Daerah Mersing, Jalan Ismail, 86800 Mersing, Johor.

Email : norzaherismail21@gmail.com

\section{ABSTRACT}

\begin{tabular}{ll}
\hline Pengenalan & Kanser prostat merupakan ketiga tertinggi bagi golongan lelaki di Malaysia. \\
& Data 2018 melaporkan kanser prostat mencatatkan insiden 1,807 kes \\
& berbanding 1,186 kes pada tahun 2014. Kanser prostat ini turut memberi \\
& kesan terhadap beban penyakit serta beban ekonomi kepada negara dan \\
& memberi kesan terhadap kualiti hidup pesakit terutamanya pesakit berumur \\
& melebihi 65 tahun. Kajian ini dilakukan bagi mengukur tahap kualiti hidup \\
& pesakit kanser prostat dan menentukan faktor-faktor yang mempengaruhi \\
& kualiti hidup pesakit tersebut. \\
& Reka bentuk kajian adalah keratan rentas yang dilakukan dari Januari 2018 \\
& sehingga Disember 2018. Sampel kajian terdiri daripada pesakit kanser \\
& prostat yang didiagnos dan mendapatkan rawatan di Klinik Urologi, Jabatan \\
& Pembedahan dan Jabatan Onkologi dari tahun 2008 hingga 2017. Kajian \\
& menggunapakai set soal selidik EORTC QLQ-C30 dan EORTC QLQ-PR25 \\
& yang telah diterjemahkan ke Bahasa Melayu. \\
Hasil Kajian & Seramai 193 pesakit telah mengambil bahagian. Analisis mendapati tahap \\
& kanser memberi perbezaan yang signifikan kepada status kesihatan serta \\
& fungsi dan simptom kanser prostat (p < 0.001). \\
& Kesimpulannya, analisis faktor penentu mendapati umur, skor Gleason dan \\
Rumusan & juga tahap lewat kanser merupakan faktor penentu kepada kualiti hidup \\
& pesakit kanser prostat (p < 0.05). Langkah kesedaran, saringan serta rawatan \\
& awal dilihat perlu dipertingkatkan bagi meningkatkan tahap kualiti hidup \\
Kata Kunci & pesakit kanser prostat di hopital ini. \\
& Kualiti hidup - kanser prostat - faktor penentu.
\end{tabular}

Article history:

Received: 29 November 2020

Accepted: 8 June 2021

Published: 1 March 2022 


\section{PENGENALAN}

Kanser prostat merupakan ketiga tertinggi bagi golongan lelaki di Malaysia. Data 2018 melaporkan kanser prostat mencatatkan insiden 1,807 kes berbanding 1,186 kes pada tahun 2014. ${ }^{1}$ Kanser prostat ini turut memberi kesan terhadap beban penyakit serta beban ekonomi kepada negara dan memberi kesan terhadap kualiti hidup pesakit terutamanya pesakit berumur melebihi 65 tahun. Kualiti hidup bermaksud keadaan kesejahteraan yang melibatkan kemampuan pesakit untuk menjalani aktiviti harian mereka termasuk keupayaan fizikal, status psikologi, komunikasi dan kesejahteraan sosial serta kepuasan pesakit terhadap fungsi dan kawalan penyakit. $^{2}$ Beberapa kajian terdahulu juga mempunyai beberapa definisi tentang kualiti hidup bagi pesakit. Antaranya Gotay $(1992)^{3}$ menyatakan kualiti hidup adalah satu keadaan terdiri daripada dua komponen iaitu kebolehan melakukan aktiviti harian dari segi fizikal, psikologikal, dan sosial dan kedua kepuasan terhadap tahap fungsi dan kawalan penyakit.

Knippenberg (1988) ${ }^{4}$ pula melaporkan kualiti sebagai sesuatu ukuran subjektif tentang kebaikan dan kepuasan seseorang itu secara keseluruhan. Calman $(1984)^{5}$ pula menyatakan kualiti hidup sebagai jurang terhadap keinginan dengan pencapaian pesakit. Lebih kecil jurang menandakan kualiti hidup yang lebih baik. Kajian ini dilakukan bagi mengukur tahap kualiti hidup pesakit kanser prostat dan menentukan faktor-faktor yang mempengaruhi kualiti hidup pesakit tersebut.

\section{METODOLOGI}

Reka bentuk kajian adalah tirisan melintang. Sampel kajian terdiri daripada pesakit kanser prostat yang didiagnos dan mendapatkan rawatan di Klinik Urologi, Jabatan Pembedahan dan Jabatan Onkologi dari tahun 2008 hingga 2017. Tempoh kajian dilakukan bermula dari Januari sehingga Disember 2018. Semasa kajian pesakit kanser prostat telah diberi set soal selidik yang telah diterjemahkan kepada Bahasa Melayu untuk dijawab. Sekiranya pesakit mempunyai masalah berkaitan set soalselidik, bantuan penjelasan diberikan oleh penyelidik. Data pesakit berkaitan rekod klinikal dan rawatan pula diambil dari rekod perubatan pesakit. Bagi pesakit yang mempunyai jenis kanser lain, bukan warganegara Malaysia serta yang didiagnos sebelum 2008 dan selepas 2017 dikecualikan daripada kajian ini. Kajian ini juga telah menerima kelulusan daripada Jawatankuasa Etika dan Penyelidikan UKM, (FF-2017-249)

Material
Borang kajian soal selidik yang digunakan terdiri daripada dua set soalan iaitu EORTC QLQ-C30 dan EORTC QLQ-PR25. Bagi set soalan soal selidik EORTC QLQ-C30, ianya telah mula dibangunkan pada tahun 1987 dengan jumlah 36 soalan. ${ }^{6}$ Set soalan ini dibangunkan dengan tujuan spesifik untuk mengukur kualiti hidup pesakit kanser tanpa mengira lokaliti, kaum dan juga budaya. ${ }^{7,8}$ Kemudian set soalan ini dilakukan penambahbaikkan sehinggalah kepada set soalan versi ketiga dengan jumlah akhir sebanyak 30 soalan. $^{9}$

Bagi set soalan kanser prostat EORTC QLQ-PR25 pula telah dibangunkan oleh EORTC Genito-Urinary Tract Cancer Cooperative Group yang terdiri daripada 25 soalan dan dibangunkan mengikut garis panduan yang telah ditetapkan oleh modul pembangunan Organisasi Kajian dan Rawatan Kanser Eropah, EORTC 10 dan pertama kali digunakan di Sweden. ${ }^{11}$ Set soalan ini juga telah dilakukan proses validasi kebolehpercayaan di banyak pusat kajian di seluruh dunia. ${ }^{12}$ Set soalan terjemahan Bahasa Melayu telah dilakukan proses validasi di pusat kajian yang sama sebelum kajian ini dilakukan dan mempunyai kadar keboleypercayaan yang baik dengan pekali Cronbach-alpha 0.913 (EORTC QLQ-C30) and 0.829 (EORTC PR-25). ${ }^{13}$

Analisis data

Data dianalisis dengan menggunakan Statistical Package for Social Science (SPSS) versi 21. Data deskriptif telah dibentangkan dalam bentuk frekuensi dan peratusan. Di dalam analisis univariabel kualiti hidup menggunakan kaedah ANOVA sehala bagi mengukur perbezaan skor berdasarkan faktor tahap kanser dan jenis rawatan yang diterima pesakit. Bagi analisis multivariabel pula, regresi linear multiple (multiple linear regression) telah digunakan dalam menentukan faktor-faktor yang mempengaruhi fungsi dan juga simptom-simptom terhadap kualiti hidup pesakit kanser prostat. Aras keertian ditetapkan pada nilai 0.05 dan selang keyakinan pada $95 \%$.

\section{HASIL KAJIAN}

Secara keseluruhan mendapati seramai 193 orang pesakit kanser prostat telah mengambil bahagian. Daripada jumlah itu, hampir separuh (49.7\%) adalah terdiri daripada pesakit yang berumur 75 tahun dan ke atas manakala kira-kira $39.9 \%$ adalah mereka yang berumur 65 tahun sehingga 74 tahun. Pesakit kanser yang terdiri daripada bangsa Cina mencatatkan 59.1\% daripada jumlah responden diikuti pesakit berbangsa Melayu dengan 36.8\% dan pesakit bangsa India mencatatkan hanya $4.1 \%$.

Taburan faktor-faktor klinikal mendapati majoriti responden merupakan pesakit yang berada di Tahap 2 kanser prostat dengan 119 orang pesakit 
(61.7\%). Skor Gleason pula mencatatkan 34.7\% adalah terdiri daripada pesakit yang mempunyai skor Gleason $\leq 6,29.5 \%$ mempunyai skor Gleason tujuh manakala selebihnya $35.8 \%$ mempunyai skor Gleason $\geq 8$. Bilangan pesakit yang mempunyai komplikasi metastasis kanser pula adalah seramai 82 orang $(42.5 \%)$ dan komplikasi sebaran kanser ke nodus limfa seramai $25.9 \%$.
Faktor jenis rawatan pula menunjukkan rawatan jenis survelan aktif mencatatkan $8.8 \%$ atau 17 orang pesakit diikuti oleh jenis rawatan intervensi pembedahan dengan 18 orang pesakit (9.3\%) manakala pesakit kanser yang menerima terapi hormon mencatatkan $35.2 .1 \%$ dengan 68 orang pesakit.

Jadual 1 Taburan sosiodemografi pesakit $(\mathrm{N}=193)$

\begin{tabular}{llrr}
\hline & Faktor & $\begin{array}{c}\text { Bil. Pesakit } \\
(\mathrm{n})\end{array}$ & $\begin{array}{c}\text { Peratusan } \\
(\%)\end{array}$ \\
\hline Umur & $<65$ & 20 & 10.4 \\
& $\geq 65-74$ & 77 & 39.9 \\
\multirow{5}{*}{ Bangsa } & $\geq 75$ & 96 & 49.7 \\
& Melayu & 71 & 36.8 \\
Taraf Perkahwinan & Cina & 114 & 59.1 \\
& India & 8 & 4.1 \\
Pandapatan & Bujang / Duda & 39 & 20.2 \\
& Berkahwin & 154 & 79.8 \\
& $<$ RM 3,860 & 51 & 26.4 \\
Pendidikan & $\geq$ RM 3,860-RM8,319 & 94 & 48.7 \\
& $\geq$ RM 8,320 & 48 & 24.9 \\
& Rendah /Tidak formal & 93 & 48.2 \\
& Menengah ke atas & 100 & 51.8 \\
\hline
\end{tabular}

Jadual 2 Taburan pesakit kanser prostat berdasarkan faktor klinikal $(\mathrm{N}=193)$

\begin{tabular}{llrr}
\hline & Faktor & $\begin{array}{c}\text { Bil. Pesakit } \\
(\mathrm{n})\end{array}$ & $\begin{array}{c}\text { Peratusan } \\
(\%)\end{array}$ \\
\hline Tahap Kanser & Tahap 1 & 18 & 9.3 \\
& Tahap 2 & 119 & 61.7 \\
& Tahap 3 & 45 & 23.3 \\
& Tahap 4 & 11 & 5.7 \\
Skor Gleason & $\leq 6$ & 67 & 34.7 \\
& 7 & 57 & 29.5 \\
Tahap PSA (ng/ml) & $\geq 8$ & 69 & 35.8 \\
& $\geq 10.00$ & 121 & 62.7 \\
\multirow{5}{*}{ Nodus Limfa } & $\geq 10.00-19.99$ & 21 & 10.9 \\
& $\geq 20.00$ & 47 & 24.4 \\
Metastasis & Ya & 50 & 25.9 \\
& Tidak & 143 & 74.1 \\
Rawatan & Ya & 82 & 42.5 \\
& Tidak & 111 & 57.5 \\
& Survelan Aktif & 17 & 8.8 \\
& Terapi Hormon & 68 & 35.2 \\
& Pembedahan & 18 & 9.3 \\
& Terapi Kombinasi & 90 & 46.7 \\
\hline
\end{tabular}

Skor Kualiti Hidup

Hasil analisis mendapati perbezaan yang signifikan terhadap status kesihatan global pesakit (nilai $p$ $<0.01)$ terhadap tahap kanser. Perbezaan yang signifikan juga dapat dilihat daripada fungsi - fungsi fizikal, peranan, emosi, kognitif dan juga sosial (nilai $p<0.001)$. Dari segi skala simptom pula menunjukkan perbezaan tahap kanser memberi perbezaan yang signifikan terhadap simptom keletihan, kesakitan kanser, sesak nafas, insomnia, hilang selera makan dan juga sembelit. Namun didapati tidak terdapat perbezaan yang signifikan 
dilihat daripada analisis simptom loya dan muntah, cirit-cirit dan juga masalah kewangan.

Analisis bagi kualiti hidup berdasarkan soal selidik EORTC QLQ-PR25 pula mendapati perbezaan tahap kanser pesakit memberi perbezaan yang signifikan kepada fungsi seksual, simptom urinari, simptom penghadaman dan juga simptom inkontinen (nilai $\mathrm{p}<0.001$ ) tetapi tidak memberi perbezaan yang signifikan kepada fungsi aktiviti seksual dan juga simptom berkaitan rawatan.

Jadual 3 Skor kualiti hidup berdasarkan perbezaan tahap kanser menggunakan EORTC QLQ-C30

\begin{tabular}{|c|c|c|c|c|c|c|}
\hline & $\begin{array}{c}\text { Tahap 1 } \\
\text { Min (S.P) } \\
\mathrm{n}=18\end{array}$ & $\begin{array}{c}\text { Tahap } 2 \\
\text { Min (S.P) } \\
\mathrm{n}=119\end{array}$ & $\begin{array}{c}\text { Tahap } 3 \\
\text { Min (S.P) } \\
\mathrm{n}=45\end{array}$ & $\begin{array}{c}\text { Tahap } 4 \\
\text { Min (S.P) } \\
\mathrm{n}=11\end{array}$ & $\begin{array}{c}F \\
\text { (Darjah } \\
\text { Kebebasan) }\end{array}$ & Nilai- $p$ \\
\hline $\begin{array}{l}\text { Status Kesihatan Global } \\
\text { Skala Fungsi }\end{array}$ & $76.85(8.36)$ & $69.61(12.30)$ & $54.26(8.64)$ & $45.45(9.34)$ & $37.80(3)$ & $<0.001$ \\
\hline Fizikal & $63.70(33.08)$ & $80.56(21.95)$ & $59.85(26.11)$ & $24.85(9.47)$ & $24.20(3)$ & $<0.001$ \\
\hline Peranan & 71.30 (15.97) & $81.93(13.30)$ & 52.59 (19.99) & $27.27(21.10)$ & $68.50(3)$ & $<0.001$ \\
\hline Emosi & 87.04 (9.99) & $73.95(15.40)$ & $61.85(14.70)$ & $37.12(16.82)$ & $32.90(3)$ & $<0.001$ \\
\hline Kognitif & $82.41(8.98)$ & $75.49(14.85)$ & $71.85(17.70)$ & $36.36(16.36)$ & $24.64(3)$ & $<0.001$ \\
\hline Sosial & $92.74(11.75)$ & 68.35 (22.69) & $34.44(21.14)$ & $18.18(18.94)$ & $55.46(3)$ & $<0.001$ \\
\hline Skala Simptom & & & & & & \\
\hline Keletihan & $13.58(12.96)$ & $25.77(15.64)$ & $68.40(14.20)$ & $88.89(8.61)$ & $150.23(3)$ & $<0.001$ \\
\hline Loya dan Muntah & $12.96(17.67)$ & $20.59(22.52)$ & $17.78(21.44)$ & $13.64(17.98)$ & $0.95(3)$ & 0.418 \\
\hline Kesakitan & $21.29(18.79)$ & $30.95(18.70)$ & $62.59(23.44)$ & $84.85(11.68)$ & $53.41(3)$ & $<0.001$ \\
\hline Sesak Nafas & $14.81(20.52)$ & $11.48(19.13)$ & $26.67(28.07)$ & $39.39(32.72)$ & $8.84(3)$ & $<0.001$ \\
\hline Insomnia & $5.56(12.78)$ & $35.29(25.04)$ & $60.74(17.82)$ & $72.73(32.72)$ & $34.20(3)$ & $<0.001$ \\
\hline Hilang Selera & $7.41(14.26)$ & $25.77(25.47)$ & $41.48(31.10)$ & $81.82(17.41)$ & $23.39(3)$ & $<0.001$ \\
\hline Sembelit & $5.56(12.78)$ & $13.73(20.08)$ & $50.37(26.23)$ & $72.73(25.03)$ & $55.07(3)$ & $<0.001$ \\
\hline Cirit-Birit & $0.00(0.00)$ & $12.89(22.59)$ & $9.63(18.29)$ & $9.09(21.56)$ & $2.14(3)$ & 0.096 \\
\hline Masalah Kewangan & $59.26(29.27)$ & $63.87(33.21)$ & $71.85(30.94)$ & $54.55(26.03)$ & $1.32(3)$ & 0.271 \\
\hline
\end{tabular}

Nilai purata dinilai dalam \%, nilai-p signifikan pada $<0.05$

Jadual 4 Skor kualiti hidup berdasarkan perbezaan tahap kanser menggunakan EORTC QLQ-PR25

\begin{tabular}{|c|c|c|c|c|c|c|}
\hline & $\begin{array}{c}\text { Tahap 1 } \\
\text { Min (S.P) } \\
\mathrm{n}=18\end{array}$ & $\begin{array}{c}\text { Tahap } 2 \\
\text { Min (S.P) } \\
n=119\end{array}$ & $\begin{array}{c}\text { Tahap } 3 \\
\text { Min (S.P) } \\
\mathrm{n}=45\end{array}$ & $\begin{array}{c}\text { Tahap } 4 \\
\text { Min (S.P) } \\
n=11\end{array}$ & $\begin{array}{c}F \\
\text { (Darjah } \\
\text { Kebebasan) }\end{array}$ & Nilai- $p$ \\
\hline \multicolumn{7}{|l|}{ Fungsi } \\
\hline Aktiviti Seksual & $90.74(11.75)$ & $86.41(13.19)$ & $83.70(14.86)$ & $87.88(10.78)$ & $1.28(3)$ & 0.282 \\
\hline Fungsi Seksual & $68.52(9.29)$ & $64.36(10.95)$ & $43.89(17.26)$ & $31.06(8.41)$ & $50.80(3)$ & $<0.001$ \\
\hline \multicolumn{7}{|l|}{ Gejala Simptom } \\
\hline Urinari & $8.56(8.39)$ & $27.03(12.52)$ & $55.28(13.37)$ & $70.45(9.58)$ & $115.90(3)$ & $<0.001$ \\
\hline Penghadaman & $1.85(3.56)$ & $12.47(13.06)$ & $29.63(17.99)$ & $43.18(14.35)$ & $36.60(3)$ & $<0.001$ \\
\hline Berkaitan Rawatan & $15.74(8.14)$ & $22.32(11.11)$ & $23.21(14.13)$ & $28.28(9.11)$ & $0.68(3)$ & 0.560 \\
\hline Inkontinens & $1.78(2.33)$ & $1.67(3.44)$ & $35.19(28.89)$ & $45.45(50.05)$ & $10.45(3)$ & $<0.001$ \\
\hline
\end{tabular}

Skor Kualiti Hidup berdasarkan Jenis Rawatan Analisis yang dilakukan terhadap skala fungsi menunjukkan tiada perbezaan yang signifikan didapati antara jenis-jenis rawatan yang diterima pesakit dengan skor kualiti hidup pesakit kanser prostat (nilai $p>0.05$ ). Hal ini menunjukkan bahawa pesakit-pesakit kanser prostat dapat berfungsi dengan tahap yang hampir sama tanpa mengira jenis rawatan yang diterima. Malahan analisis kedua-dua set soal selidik EORTC QLQ-C30 dan juga EORTC QLQ PR25 ini turut menunjukkan tidak berlaku perbezaan yang signifikan terhadap simptom-simptom pesakit kanser yang mendapatkan rawatan survelan aktif, terapi hormon, intervensi pembedahan mahupun terapi kombinasi (Jadual 5-6).
Faktor Penentu Kualiti Hidup Pesakit Kanser Prostat Daripada analisis mendapati status kesihatan global dipengaruhi oleh tahap kanser, fungsi fizikal dipengaruhi oleh faktor umur, tahap penyakit kanser, skor Gleason dan rawatan jenis rawatan. Faktor yang menentukan fungsi peranan pula terdiri daripada umur, tahap penyakit kanser, skor Gleason dan juga jenis rawatan (Jadual 7).

Fungsi emosi serta fungsi seksual pesakit kanser prostat didapati mempunyai korelasi dengan faktor umur dan tahap kanser sementara fungsi kognitif seorang pesakit kanser akan dipengaruhi oleh faktor tahap kanser pesakit. Selain itu, faktor tahap penyakit dan skor Gleason mempunyai pengaruh yang signifikan kepada fungsi sosial pesakit kanser. 
Bagi analisis simptom pula mendapati tahap kanser dan skor Gleason menjadi faktor penentu kepada simptom kesakitan, hilang selera, urinari dan penghadaman manakala simptom sembelit dan penghadaman hanya ditentukan oleh faktor tahap kanser sahaja.

Jadual 5 Skor kualiti hidup berdasarkan perbezaan jenis rawatan menggunakan soal selidik EORTC QLQ-C30

\begin{tabular}{|c|c|c|c|c|c|c|}
\hline & $\begin{array}{c}\text { Survelan } \\
\text { Aktif } \\
\text { Min (S.P) } \\
\mathrm{n}=17 \\
\end{array}$ & $\begin{array}{c}\text { Terapi Hormon } \\
\text { Min (S.P) } \\
n=68\end{array}$ & $\begin{array}{c}\text { Intervensi } \\
\text { Pembedahan } \\
\text { Min (S.P) } \\
\mathrm{n}=18 \\
\end{array}$ & $\begin{array}{c}\text { Terapi Kombinasi } \\
\text { Min (S.P) } \\
n=90\end{array}$ & $\begin{array}{c}F \\
\text { (Darjah } \\
\text { Kebebasan) }\end{array}$ & Nilai $p$ \\
\hline EORTC QLQ-C30 & & & & & & \\
\hline $\begin{array}{l}\text { Status Kesihatan } \\
\text { Global }\end{array}$ & $71.08(15.62)$ & $65.23(13.80)$ & $63.89(10.30)$ & $64.67(14.66)$ & $1.07(3)$ & 0.362 \\
\hline Skala Fungsi & & & & & & \\
\hline Fizikal & $62.75(31.01)$ & $68.96(29.98)$ & $71.48(25.13)$ & $73.47(26.17)$ & $0.873(3)$ & 0.456 \\
\hline Peranan & $61.76(22.64)$ & $69.25(23.74)$ & $72.22(22.14)$ & $73.33(21.58)$ & $1.46(3)$ & 0.226 \\
\hline Emosi & $77.45(20.36)$ & $71.84(20.04)$ & $69.91(16.70)$ & $68.17(16.89)$ & $1.48(3)$ & 0.223 \\
\hline Kognitif & $74.51(19.65)$ & $71.84(17.44)$ & $72.22(17.15)$ & 73.67 (18.07) & $0.18(3)$ & 0.911 \\
\hline Sosial & $73.53(34.39)$ & $60.92(30.83)$ & $62.96(25.28)$ & $56.33(27.30)$ & $1.86(3)$ & 0.138 \\
\hline Skala Simptom & & & & & & \\
\hline Keletihan & $34.64(32.13)$ & $38.12(28.09)$ & 38.89 (21.98) & $38.67(26.59)$ & $0.11(3)$ & 0.954 \\
\hline Loya dan Muntah & $15.69(18.13)$ & $16.09(23.15)$ & $21.29(22.73)$ & $20.50(21.17)$ & $0.70(3)$ & 0.552 \\
\hline Kesakitan & $43.14(30.08)$ & $38.51(27.43)$ & $43.52(21.50)$ & $40.67(26.09)$ & $0.25(3)$ & 0.865 \\
\hline Sesak Nafas & $13.73(20.61)$ & $19.54(27.24)$ & $11.11(19.80)$ & $17.00(22.96)$ & $0.69(3)$ & 0.560 \\
\hline Insomnia & $39.22(37.70)$ & $37.36(29.34)$ & $44.44(30.25)$ & $42.00(26.09)$ & $0.45(3)$ & 0.719 \\
\hline Hilang Selera & $21.57(31.05)$ & $31.03(29.19)$ & 24.07 (31.94) & 33.67 (29.77) & $1.15(3)$ & 0.330 \\
\hline Sembelit & $25.49(36.38)$ & $26.44(30.43)$ & $27.78(28.58)$ & $23.33(27.42)$ & $0.21(3)$ & 0.890 \\
\hline Cirit-Birit & $7.84(22.14)$ & $8.62(17.17)$ & $20.37(23.26)$ & $10.67(21.65)$ & $1.63(3)$ & 0.184 \\
\hline Masalah Kewangan & $60.78(29.42)$ & $64.37(35.24)$ & $66.67(37.92)$ & $65.33(29.93)$ & $0.12(3)$ & 0.948 \\
\hline
\end{tabular}

Jadual 6 Skor kualiti hidup berdasarkan perbezaan jenis rawatan menggunakan soal selidik EORTC QLQ-PR25

\begin{tabular}{|c|c|c|c|c|c|c|}
\hline & $\begin{array}{c}\text { Survelan } \\
\text { Aktif } \\
\text { Min (S.P) } \\
\mathrm{n}=17 \\
\end{array}$ & $\begin{array}{c}\text { Terapi Hormon } \\
\text { Min (S.P) } \\
n=68\end{array}$ & $\begin{array}{c}\text { Intervensi } \\
\text { Pembedahan } \\
\text { Min (S.P) } \\
\mathrm{n}=18 \\
\end{array}$ & $\begin{array}{c}\text { Terapi Kombinasi } \\
\text { Min (S.P) } \\
n=90\end{array}$ & $\begin{array}{c}F \\
\text { (Darjah } \\
\text { Kebebasan) }\end{array}$ & Nilai- $p$ \\
\hline \multicolumn{7}{|l|}{ Fungsi } \\
\hline Aktiviti Seksual & $89.22(13.10)$ & $85.06(12.75)$ & $85.19(15.00)$ & $86.67(13.61)$ & $0.50(3)$ & 0.685 \\
\hline $\begin{array}{l}\text { Fungsi Seksual } \\
\text { Gejala Simptom }\end{array}$ & $58.82(17.30)$ & $58.06(16.18)$ & $59.26(15.36)$ & $57.67(17.23)$ & $0.06(3)$ & 0.980 \\
\hline Urinari & $29.41(23.27)$ & $33.19(20.43)$ & $34.26(18.58)$ & $35.92(20.49)$ & $0.58(3)$ & 0.629 \\
\hline Penghadaman & $14.22(19.27)$ & $14.94(15.90)$ & $18.06(18.58)$ & $18.92(17.12)$ & $0.83(3)$ & 0.478 \\
\hline Berkaitan Rawatan & 22.55 (14.89) & $22.22(11.91)$ & $21.91(12.42)$ & $22.28(11.12)$ & $0.01(3)$ & 0.999 \\
\hline Inkontinens & $11.11(9.99)$ & $4.00(3.66)$ & $6.25(3.35)$ & $5.48(4.57)$ & $0.32(3)$ & 0.811 \\
\hline
\end{tabular}

Jadual 7 Faktor penentu kualiti hidup pesakit kanser prostat

\begin{tabular}{|c|c|c|c|c|c|c|}
\hline \multirow[t]{2}{*}{ Skala } & \multicolumn{2}{|l|}{ Umur } & \multicolumn{2}{|c|}{ Skor Gleason } & \multicolumn{2}{|c|}{ Tahap Lewat Kanser } \\
\hline & b (S.K 95\%) & nilai- $p$ & b (S.K 95\%) & nilai- $p$ & b (S.K 95\%) & nilai- $p$ \\
\hline Kesihatan Global & & & & & $\begin{array}{r}-19.16 \\
(-22.94,-15.37)\end{array}$ & $<0.001$ \\
\hline Skala Fungsi & & & & & & \\
\hline Fizikal & $\begin{array}{r}-25.20(-31.77,- \\
18.63)\end{array}$ & $<0.001$ & $8.56^{\mathrm{d}}(0.51,16.61)$ & 0.037 & $-26.10(-32.95,-19.25)$ & $<0.001$ \\
\hline Peranan & $14.85^{\mathrm{a}}(6.51,23.19)$ & $<0.001$ & $\begin{array}{l}8.48^{\mathrm{d}}(2.37,14.59) \\
-8.00^{\mathrm{f}}(13.87,2.10)\end{array}$ & $\begin{array}{l}<0.001 \\
<0.001\end{array}$ & $-32.15(-37.35,-26.95)$ & $<0.001$ \\
\hline Emosi & $-0.44^{\mathrm{a}}(-0.68,-0.19)$ & $<0.001$ & & & $0.52(0.37,0.67)$ & $<0.001$ \\
\hline Kognitif & & & & & $0.31(0.14,0.48)$ & $<0.001$ \\
\hline Sosial & & & $-0.33^{\mathrm{f}}(-0.58,-0.08)$ & 0.011 & $1.14(0.93,1.36)$ & $<0.001$ \\
\hline $\begin{array}{l}\text { Seksual } \\
\text { Skala Simptom }\end{array}$ & $8.69^{\mathrm{a}}(1.79,15.58)$ & 0.014 & & & $-23.38(-27.64,-19.12)$ & $<0.001$ \\
\hline Kesakitan & & & $-7.19^{\mathrm{a}}(-13.21,-1.16)$ & 0.020 & $36.12(29.80,42.44)$ & $<0.001$ \\
\hline Hilang Selera & & & $26.41^{\mathrm{f}}(17.70,35.12)$ & $<0.001$ & $24.13(17.70,35.12)$ & $<0.001$ \\
\hline Urinari & & & $-5.90^{\mathrm{d}}(-10.71,-1.09)$ & 0.017 & $32.60(28.36,36.85)$ & $<0.001$ \\
\hline Sembelit & & & & & $41.12(34.20,48.04)$ & $<0.001$ \\
\hline
\end{tabular}


International Journal of Public Health Research Vol 12 No 1 2022, pp (1510-1518)

\begin{tabular}{|c|c|c|c|c|}
\hline Dyspnoe & $8.96^{\mathrm{c}}(2.34,15.57)$ & 0.008 & $17.70(10.84,24.56)$ & $\begin{array}{l}<0.001 \\
<0.001\end{array}$ \\
\hline Penghadaman & & & $20.52(15.97,25.07)$ & $<0.001$ \\
\hline$\frac{\text { Kewangan }}{\text { Nilai p beerti }}$ & $\frac{0.46^{\mathrm{a}}(0.02,0.90)}{\text { ifikan pada }<0.05}$ & $<0.001$ & & \\
\hline
\end{tabular}

\section{PERBINCANGAN}

Daripada analisis mendapati faktor penentu terhadap kualiti hidup pesakit kanser prostat adalah umur, skor Gleason dan juga tahap kanser prostat. Satu kajian pada tahun 2007 oleh Northouse dan Mood mendapati umur memainkan peranan di mana golongan lelaki yang berumur di bawah umur 65 tahun akan menunjukkan kualiti hidup yang lebih rendah. Kajian itu melaporkan pesakit berumur kurang 65 tahun mempunyai kadar tekanan dan kekecewaan yang agak tinggi yang menyumbangkan kepada perubahan gaya hidup mereka. Golongan ini juga turut melaporkan tentang masalah kewangan dan juga perubahan dari aspek fungsi sosial dan juga fungsi peranan serta perubahan matlamat hidup.

Bagi pesakit yang berumur antara 65 tahun hingga 74 tahun pula melaporkan tahap kualiti hidup yang lebih selesa dengan keadaan yang dialami mereka. Manakala terdapat kajian lain yang melaporkan pesakit yang berumur lebih dari 75 tahun mempunyai kualiti hidup yang jauh lebih baik di mana pesakit ini akan lebih terbuka dan menerima keadaan penyakit dan rawatan yang diterima mereka. Selain itu golongan pesakit yang berumur lebih dari 75 tahun juga didapati mempunyai tahap tekanan yang lebih rendah, mempunyai fungsi emosi yang lebih baik dan bersikap positif terhadap penyakit dan rawatan yang diterima mereka. ${ }^{14}$

Hasil itu turut menyerupai beberapa kajian lain oleh Baider (1998) $)^{15}$ dan juga Nijboer $(2000)^{16}$ yang melaporkan pesakit yang semakin berumur lebih mudah untuk mempunyai perubahan adaptasi kepada aktiviti harian dan mempunyai kurang tekanan kepada aspek mental, psikologi dan juga peranan. Manakala kajian oleh Kershaw $(2008)^{17}$ mendapati faktor umur turut mempengaruhi fungsi fizikal pesakit namun beliau tidak menafikan faktor ini adalah berkemungkinan disebabkan perubahan fisiologi pesakit.

Bagi tahap kanser pesakit pula mendapati kebanyakan kajian melaporkan kualiti hidup yang rendah kerap berlaku kepada pesakit yang didiagnos sebagai penghidap kanser prostat tahap lewat yang melibatkan Tahap 3 dan juga Tahap 4. Hal ini berlaku disebabkan oleh penurunan fungsi fizikal, peranan, sosial dan lain-lain lagi. ${ }^{18-22}$ Bagi kajian ini pula mendapati faktor tahap kanser prostat menjadi penentu kepada beberapa fungsi, simptom dan keadaan kesihatan global pesakit. Selain itu faktorfaktor lain seperti rawatan kepada pesakit yang melibatkan pengambilan hormon kepada pesakit kanser prostat di tahap lewat turut mempengaruhi kualiti hidup yang melibatkan fungsi fizikal, simptom keletihan dan juga fungsi seksual pesakit. ${ }^{23-27}$ Ini termasuklah kajian-kajian yang telah dibuat oleh Northouse dan juga Navon (2003) $)^{28}$ yang melaporkan pesakit kanser prostat dari semua tahap kanser sama ada awal atau pun tahap lewat mempunyai fungsi fizikal yang rendah selain melaporkan penemuan terhadap pasangan pesakit kanser yang turut mencatatkan fungsi emosi yang rendah.

Bagi pesakit kanser prostat yang berada pada tahap awal, pemilihan jenis rawatan adalah satu aspek penting bagi menyeimbangkan antara kualiti hidup pesakit dan juga keadaan penyakit. Manakala pesakit yang berada di tahap kanser lewat tanpa komplikasi metastasis, rawatan terapi kombinasi dilaporkan dapat membantu mencapai jangka hayat yang sepatutnya. Manakala pesakit yang di tahap kanser lewat, berumur dan terdapat komplikasi metastasis, rawatan sokongan paliatif melibatkan hormon terapi menjadi pilihan utama bagi mendapatkan kualiti hidup yang baik disamping mengurangkan kesan sampingan rawatan lain. ${ }^{29,30}$

Dalam hasil analisis kajian ini mendapati fungsi fizikal terhadap pesakit kanser prostat turut ditentukan oleh faktor-faktor seperti umur, tahap kanser dan juga skor Gleason. Jika dilihat dari segi fungsi fizikal, kanser prostat mungkin salah satu penyakit yang memberi stigma kepada masyarakat tentang penurunan identiti maskulin seorang lelaki. Ianya jelas digambarkan melalui keadaan pesakit yang dilihat mempunyai simptom seksual yang berkurangan di samping kesan sampingan seperti inkontinen dan juga penurunan fungsi fizikal yang agak ketara. Namun begitu, kajian oleh Bertero melaporkan fungsi fizikal ini berubah hanya selepas menerima rawatan. Beliau menyatakan kesan fungsi fizikal ini turut disebabkan oleh faktor umur selain dipengaruhi oleh keadaan pesakit itu sendiri. Menurutnya, pemilihan jenis rawatan dengan kesan sampingan rawatan kanser prostat adalah keputusan yang sangat besar bagi seorang lelaki. Namun ramai pesakit masih berharap agar fungsi fizikal dan fungsi seksual dapat kembali normal seperti sebelum rawatan. Walau bagaimanapun didapati kebanyakan pesakit kanser prostat dapat menerima kesan sampingan terhadap perubahan fungsi fizikal dan seksual dan dapat melaluinya dengan baik. ${ }^{31}$ 
Terdapat beberapa kajian yang melaporkan perubahan terhadap fungsi fizikal pesakit kanser prostat selepas mendapatkan rawatan. Di dalam kajian di Jepun oleh Namiki didapati pesakit kanser prostat yang mempunyai simptom masalah kawalan air kencing dan masalah penghadaman selepas melakukan pembedahan prostatektomi atau radioterapi akan berisiko untuk mempunyai masalah fungsi fizikal yang lebih teruk berbanding pesakit yang menerima jenis rawatan berbeza. Sementara itu, kajian di German pula mendapati $75 \%$ pesakit yang melakukan pembedahan prostatektomi radikal melalui kaedah retro-pubik mempunyai fungsi fizikal yang lebih baik seperti keadaan asal selepas tempoh satu tahun pembedahan dilakukan. Namun kajian itu mendapati kadar pemulihan daripada kesihatan mental kesan daripada diagnosis dan rawatan kanser prostat agak sukar dipulihkan dan memakan masa yang lebih lama berbanding fungsi fizikal. ${ }^{32}$

Kajian oleh Kabir $(2008)^{33}$ dan Freedland $(2009)^{34}$ menunjukkan pesakit yang berada di tahap lewat kanser sebenarnya mempunyai perkaitan dengan jenis rawatan yang diterima seperti pengambilan ubatan anti-androgen yang membawa kepada kesan sampingan yang signifikan meliputi penurunan fungsi seksual, keletihan, penurunan fungsi kognitif dan juga perubahan komposisi badan melibatkan sindrom metabolisma. Kajian ini pula didapati mempunyai persamaan dengan kajian-kajian lain seperti yang dilaporkan oleh Dacal $(2006)^{24}$ dan juga Herr dan O'Sullivan (2000) $)^{35}$ yang turut menyatakan pesakit yang menerima rawatan hormon anti-androgen mempunyai kesan sampingan penurunan fungsi fizikal yang signifikan.

Beberapa kajian lain oleh Bennett (2005), ${ }^{36}$ Dirksen (2009) ${ }^{37}$ dan Couper (2010) ${ }^{38}$ melaporkan prevalen pesakit kanser prostat yang mempunyai peningkatan risiko untuk menghadapi masalah mental yang serius termasuk anxieti, depressi, penyakit kardiovaskular dan turut berisiko untuk mencederakan diri sendiri mencecah sehingga 20\% sehingga $50 \%$ bergantung kepada populasi berbeza. Malahan terdapat juga kajian yang melaporkan terdapat juga pesakit yang mula menghadapi simptom anxieti dan depressi sejurus didiagnos dengan kanser prostat setempat atau pun tahap agresif.

\section{KESIMPULAN}

Kajian mendapati faktor penentu kepada kualiti hidup pesakit kanser prostat adalah umur, skor Gleason dan juga tahap lewat kanser. Justeru langkah pencegahan seperti meningkatkan tahap kesedaran, saringan awal dan juga rawatan awal pesakit dilihat mampu memberi tahap kualiti hidup yang lebih baik kepada pesakit kanser prostat.

\section{RUJUKAN}

1. Global Cancer Data: GLOBOCAN; 2018. Available

from:

https://www.uicc.org/news/global-cancerdata-globocan-

2018\#: :text=What\%20is\%20GLOBOCAN $\% 3 \mathrm{~F}$,for $\% 20$ all $\% 20$ cancer $\% 20$ sites $\% 20$ com bined.

2. WHOQOL Group. Study protocol for the World Health Organization project to develop a quality of life assessment instrument (WHOQOL). Qual Life Res 1993;2: 153-159.

3. Gotay CC, Korn EL, McCabe MS et al. 1992.Quality-of-life assessment in cancer treatment protocols: research issues in protocol development. J Natl Cancer Inst. 1992; 84:575-579.

4. Knippenberg FC, de Haes JC. Measuring the quality of life of cancer patients: psychometric properties of instruments. J Clin Epidemiol. 1988; 41:1043-1053.

5. Calman KC. Quality of life in cancer patients - an hypothesis. J Med Ethics. 1984; 10:124-127.

6. Aaronson NK, Bullinger M, Ahmedzai S. A modular approach to quality-of-life assessment in cancer clinical trials. Recent Results Cancer Res. 1988; 111:231-49.

7. Aaronson NK, Ahmedzai S, Bergman B, Bullinger M, Cull A, Duez NJ, et al. The European Organisation for Research and Treatment of Cancer QLQ-C30: A qualityof-life instrument for use in international clinical trials in oncology. Journal of the National Cancer Institute. 1993; 85: 365376.

8. Fayers P, Bottomley A. Quality of life research within the EORTC-the EORTC QLQ-C30. European Organisation for Research and Treatment of Cancer. Eur $\mathbf{J}$ Cancer. 2002;38 Suppl 4: S125-33.

9. Bjordal K, de Graeff A, Fayers PM, et al. A 12 country field study of the EORTC QLQC30 (version 3.0) and the head and neck cancer specific module (EORTC QLQH\&N35) in head and neck patients. EORTC Quality of Life Group.Eur J Cancer. 2000; 36:1796-807.

10. Sprangers MA, Cull A, Bjordal K, et al.1993.The European Organization for Research and Treatment of Cancer. Approach to quality of life assessment: guidelines for developing questionnaires modules. EORTC Study Group on Quality of Life.Qual Life Res.; 2:287-95. 
11. Borghede G, Sullivan M. Measurement of quality of life in localized prostatic cancer patients treated with radiotherapy. Development of a prostate cancer-specific module supplementing the EORTC QLQc30.Qual Life Res.1996; 5: 212-22.

12. Aaronson LS, Pallikkathayil L, Crighton F. 2003. A Qualitative Investigation of Fatigue Among Healthy Working Adults. West J Nurs Res. 2003; 25(4):419- 433.

13. Ismail N, Shah S, Taib S, Mat SN, \& Safian N. Internal Consistency Study of EORTC QLQ-C30 and QLQ-PR25 Questionnaires for Quality-of-Life assessment among prostate cancer patients in a University Hospital, Kuala Lumpur Malaysia. International Journal of Public Health Research. 2020; 10(1).

14. Bowman KF, Rose JH, \& Deimling GT. Appraisal of the cancer experience by family members and survivors in long-term survivorship. Psycho-Oncology. 2006; 15, I834-845.

15. Baider L, Koch U, Esacson R, \& De-Nour AK. Prospective study of cancer patients and their spouses: The weakness of marital strength. Psycho-Oncology. 1998; 7(1), 4956.

16. Nijboer C, Triemstra M, Tempelaar R, Mulder M, Sanderman R, \& van den Bos GAM. Patterns of caregiver experiences among partners of cancer patients. The Gerontologist. 2000; 40(6), 738-746.

17. Kershaw TS, Mood DW, Newth Get al. Longitudinal analysis of a model to predict quality of life in prostate cancer patients and their spouses. Annals of Behavioral Medicine. 2008; 36(2), 117-128.

18. Albersten PC, Stanford JL. Quality of life following localized prostate cancer treated initially with androgen deprivation therapy or no therapy. Journal of the National Cancer Institute. 2002; 94(6), 430-437.

19. Kornblith H. Naturalism: Both Metaphysical and Epistemological. Midwest Studies in Philosophy. 1994; 19: 39-52. Available

from: https://doi.org/10.1111/j.14754975.1994.tb00278.x.

20. Kornblith AB, Herndon JE, II Zuckerman E, Viscoli CM, Horwitz RI, Cooper MR, Harris L, Tkaczuk KH, Perry MC, Budman D, Norton L, Holland JC. Social support as a buffer to the psychological impact of stressful life events in women with breast cancer. Cancer. 2001; 91: 443454. Available

from: https://doi.org/10.1002/10970142(20010115)91:2<443::AIDCNCR1020>3.0.CO;2-Z.

21. Namiki S, Saito S, Tochigi T, Ioritani N, Terai A \& Arai Y. 2007. Impact of salvage therapy for biochemical recurrence on health-related quality of life following radical prostatectomy. International Journal of Urology. 2007; 14, 186-191.

22. Northouse LL, Mood DW, Montie JE, Sandler HM, Forman JD, Hussain M, Kershaw T. Living with prostate cancer: Patients' and spouses' psychosocial status and quality of life. Journal of Clinical Oncology. 2007; 25(27), 4171-4177.

23. Basaria S, Lieb J, Tang AM, DeWeese T, Carducci M, Eisenberger $\mathrm{M}$ et al. Long-term effects of androgen deprivation therapy in prostate cancer patients. Clinical Endocrinology. 2002; 56, 779-786.

24. Dacal K, Sereika SM, \& Greenspan SL. Quality of life in prostate cancer patients taking androgen deprivation therapy. Journal of American Geriatric Society. 2006; 54, 8590.

25. Fowler FJ, McNaughton-Collins M, WalkerCorkery E, Elliot DB, \& Barry MJ. The impact of androgen deprivation on quality of life after radical prostatectomy for prostate carcinoma. Cancer. 2002; 95, 287-295.

26. Joly F, Alibhai SMH, Galica J, Park A, Yi Q-L, Wagner L \& Tannock IF. 2006. Impact of androgen deprivation therapy on the physical and cognitive function as well as quality of life of patients with nonmetastatic prostate cancer. The Journal of Urology. 2006; 176, 2443-2447.

27. Smith DS, Carvalhal GF, Schneider K, Krygiel J, Yan Y \& Catalona WJ. Qualityof-life outcomes for men with prostate carcinoma detected by screening. Cancer. 2000; 88, 1454-1463.

28. Navon L, \& Morag A. Advanced prostate cancer patients' relationships with their spouses following hormonal therapy. European Journal of Oncology Nursing. 2003; 7(2), 73-80.

29. Jani AB, Hellman S.Early prostate cancer: clinical decision-making. Lancet. 2003; 361(9362):1045-1053.

30. Widmark A, Klepp O, Solberg A, Damber JE, et al. Endocrine treatment, with or without radiotherapy, in locally advanced prostate cancer (SPCG-7/SFUO-3): an open 
randomised phase III trial. Lancet. 2009; 373(9660):301-308.

31. Berterö C. Altered sexual patterns after treatment for prostate cancer. Cancer Practice; 9(5):245-51.

32. Treiyer A, Anheuser P, Butow Z, Steffens J. 2011. A single center prospective study: prediction of postoperative general quality of life, potency and continence after radical retropubic prostatectomy. J Urol. 2001 ;185(5):1681-5.

33. Kabir S, Mancuso P, \& Rashid P. Androgen deprivation therapy: Managing side effects. Australian Family Physician. 2008; 37(8): 641-645.

34. Freedland SJ, Eastham J \& Shore N. Androgen deprivation therapy and estrogen deficiency induced adverse effects in the treatment of prostate cancer. Prostate Cancer and Prostatic Disease. 2009; 12, 333-338.

35. Herr HW \& O'Sullivan M. Quality of life of asymptomatic men with nonmetastatic prostate cancer on androgen deprivation therapy. The Journal of Urology. 2000; 163, 1743-1746.

36. Bennett G, Badger TA. Depression in men with prostate cancer. Oncol Nurs Forum. 2005; 32 (3): 545-556.

37. Dirksen SR, Epstein DR, Hoyt MA. Insomnia, depression, and distress among outpatients with prostate cancer. Appl Nurs Res. 2009; 22 (3): 154-158.

38. Couper JW, Love AW, Duchesne GM, Bloch S, Macvean M, Dunai JV et al. Predictors of psychosocial distress 12 months after diagnosis with early and advanced prostate cancer. Med J Aust. 2010; 193 (5 Suppl): S58-S61. 